\title{
MEDINDO PADRÕES DE GEODIVERSIDADE DA REGIÃO HIDROGRÁFICA DO TOCANTINS E ITACAIÚNAS, PARÁ, AMAZÔNIA-BRASIL
}

\author{
MEASURING PATTERNS OF GEODIVERSITY OF THE HYDROGRAPHIC \\ REGION OF TOCANTINS AND ITACAIÚNAS, PARÁ, AMAZÔNIA-BRAZIL
}

Abraão Levi dos Santos MASCARENHAS ${ }^{1}$

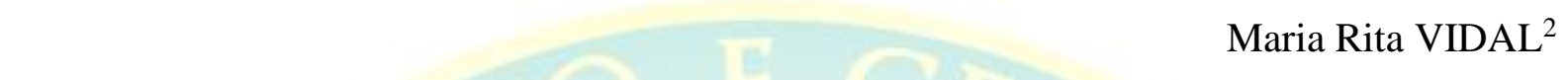

RESUMO

Diversidade de vida tem prioridade nas políticas públicas desde os anos do pós-guerra, sua importância é inegável em todos os setores da sociedade. A presente secção objetiva chamar atenção para a importância do patrimônio natural, a saber, a geodiversidade, conceito trabalhado por Murray Gray $(2004 ; 2008 ; 2018)$, que traz elementos de valorização associadas aos aspectos de valor intrínseco, cultural, estético, econômico, pesquisa e educação, nessa obra, buscamos associá-la as análises de bacias hidrográficas. Esse tipo de análise tem se restringido as questões morfométricas e hidrogeológicas, nosso desafio é demonstrar a importância da operacionalização do conceito de geodiversidade na bacia hidrográfica Tocantins e Itacaiúnas. O uso do sistema de informação geográfica permitiu organizar cinco clusteres de geodiversidade (alta, moderadamente alta, média, moderadamente baixa e baixa), na bacia hidrográfica capaz de espacializar tais padrões de geodiversidade. Espera-se que as políticas públicas de planejamento sejam capazes de absorverem esse novo conceito nas suas variáveis.

Palavras-Chaves: Geodiversidade; Cartografia; Bacia hidrográfica; Planejamento.

\section{ABSTRACT}

Diversity of life has been a priority in public policies since the post-war years, its importance is undeniable in all sectors of society. This section aims to draw attention to the importance of natural heritage, with a focus on geodiversity, a concept worked by Murray Gray (2004, 2008, 2018), which brings valuation elements associated with aspects of intrinsic value, cultural, aesthetic, economic, education and research, in this work, we seek to associate it with the analyzes of hydrographic basins. This type of analysis has been restricted to morphometric and hydrogeological issues, our challenge is demonstrate the importance of the operationalization of the concept of geodiversity in the Tocantins and Itacaiúnas hydrographic basin. The use of the geographic information system allowed the organization of five geodiversity clusters (high, moderately high, medium, moderately low and low) in the hydrographic basin able of spatialize such patterns of geodiversity. It is hoped that public planning policies will be able to absorb this new concept in its variables.

Key-words: Geodiversity; Cartography; Hydrographic basin; Planning.

\footnotetext{
${ }^{1}$ Mestre em Geografia (UFC), doutorando em Geografia Humana do em Programa Interinstitucional (DINTERUSP-Unifesspa). Docente do curso de Geografia e da Pós-graduação lato senso Geonat-Unifesspa. E-mail: abraaolevi@unifesspa.edu.br

${ }^{2}$ Doutora em Geografia (UFC), docente da Faculdade de Geografia, coordenadora do curso de pós-graduação lato senso Geonat-Unifesspa e líder do DGP-CNPq Geoecologia das Paisagens e sistemas geoinformativos da Unifesspa. E-mail: ritavidal@unifesspa.edu.br
} 


\section{RESUMEN}

Diversidad de vida tiene prioridad en las políticas públicas desde los años de la posguerra, su importancia es innegable en todos los sectores de la sociedad. La presente sección objetiva llamar la atención sobre la importancia del patrimonio natural, a saber, la geodiversidad, concepto trabajado por Murray Gray $(2004 ; 2008 ; 2018)$, que trae elementos de valorización asociados a los aspectos de valor intrínseco, cultural, estético, económico, investigación y educación, en esa obra, buscamos asociarla a los análisis de cuencas hidrográficas. Este tipo de análisis se ha restringido a las cuestiones morfométricas e hidrogeológicas, nuestro desafío es demostrar la importancia de la operacionalización del concepto de geodiversidad en la cuenca hidrográfica Tocantins y Itacaiúnas. El uso del sistema de información geográfica permitió organizar cinco clústeres de geodiversidad (alta, moderadamente alta, media, moderadamente baja y baja), en la cuenca hidrográfica capaz de espacializar tales estándares de geodiversidad. Se espera que las políticas públicas de planificación sean capaces de absorber este nuevo concepto en sus variables.

Palabras-claves: Geodiversidad; Cartografía; Cuenca hidrográfica; Planificación.

\section{INTRODUÇÃO}

A dinâmica das paisagens em bacias hidrográficas está associada e inter-relacionada com os elementos que formam uma interessante geodiversidade. Eventos pretéritos vêm configurando de forma surpreendente as paisagens contidas nos sistemas de bacias hidrográficas elaborando sua morfometria. Os demais processos ficam por conta dos fatores climáticos, a água, sem dúvida, é o dinamizador das formas de relevo e do ciclo hidrológico.

As formas de uso do solo interferem de forma significativa os ciclos da água no decorrer dos limites das bacias, a vazão e as chuvas distribuídas de forma irregular devem ser analisadas a partir do clima regional, bem como seus sistemas sinóticos perturbadores. Com todos esses fatores em associação pode-se afirmar que a geodiversidade na bacia hidrográfica é responsável pelas estabilidades e instabilidades que ocorrem na mesma.

O Estado do Pará por meio, de sua lei dos recursos hídricos, à saber, lei Estadual $n^{\circ}$ 6.381 de 2001 em consonância com a Resolução n 30 do Conselho Nacional dos Recursos Hídricos (CNRH), realizou a delimitação das suas unidades regionais de planejamentos e um total de sete (7) macro-regiões hidrográficas, todas unidades respeitaram os critérios morfológicos, hidrográficos e ecossistêmicos em sua delimitação.Ainda podemos destacar que a referida lei institui o sistema de estadual de gerenciamento de recursos hídricos. (PARÁ, 2001).

A gestão do recurso hídrico leva em consideração todas as formas de uso (consuntivo e não consuntivo) por isso pontuamos que esses critérios podem ser complementados pela caracterização do patrimônio natural como aspecto de fator abiótico como elemento da 
paisagem, a água enquanto elemento natural dotada de valor econômico se configura como recurso hídrico. Essa perspectiva deve ser levada em conta no processo de negociação do uso da água associado a ótica da geodiversidade. Gerenciar os conflitos e a degradação dos recursos hídricos entre os agentes envolvidos é o instrumento político usado como forma de administrar as visões de mundo capaz de minimizar os múltiplos conflitos. (TOZI, MASCARENHAS E POLÉN, 2018).

$\mathrm{Na}$ presente secção optarmos por caracterizar a geodiversidade das sub-regiões hidrográficas Itacaiúnas e Tocantins que de acordo com Pará, (2001) “estas são consideradas como as unidades hidrográficas de maior área, onde os afluentes menores serão agrupados de jusante para montante, respeitando os limites dos divisores d'água".

\section{MATERIAIS E MÉTODOS}

Para o desenvolvimento da presente pesquisa optou pelo método sistêmico como lastro da pesquisa em Geodiversidade, pois os fatores geológicos, geomorfológicos e pedológicos são analisados de forma integrada para se chegar a unidades homogêneas que permitam dividir a bacia hidrográfica a partir dos elementos de Geodiversidade. Além do mais, procurase dar ênfase no conceito de Gray (2004; 2008; 2018) Gray, Gordon e Brown (2013) como elemento importante para a conservação, tal qual, o conceito de Biodiversidade ${ }^{3}$.

Para Murray Gray (2011) entende o patrimônio natural como diverso em suas características geodinâmicas em um binômio complexa/múltipla fornecedor de serviços ambientais daí a analogias entre a diversidade da vida (biodiversidade) e de geodiversidade como uma "outra natureza" na busca da valorização e conservação da natureza abiótica. Assim o autor é taxativo:

The wide range of geosystem services is the direct result of the planet's geodiversity, and many abiotic values of nature are not represented in the ecosystem services approach as currently promoted [...]. This is particularly true for most of the provisioning and knowledge services; knowledge of the history of the Earth is derived from geological research, including the analysis and interpretation of geological, palaeontological, geomorphological, geochemical, geophysical and other methods, alongside the development of dating techniques. There is a strong case for conserving the important international, national and local sites that either have allowed, or have the potential to allow, scientists to reconstruct Earth history and the evolution of life. In terms of provisioning, construction materials, industrial

\footnotetext{
${ }^{3} \mathrm{O}$ conceito de biodiversidade é definido, de acordo com Edward O. Wilson (1994) como a diversidade biológica, é a assembleia de vida que levou um bilhão de anos para evoluir, sendo a chave para a preservação. Ver Wilson (1994). Diversidade de Vida. Editora Companhias das Letras.
} 
minerals and ornamental products are mainly derived from the physical Earth without the intervention of any significant role for wildlife. Society makes very extensive use of these physical materials for construction projects and the manufacture and use of items on which modern society depends, such as electronics, telecommunications, transport or energy, but it is also important that these materials are used sustainably. These and the other geosystem services deserve greater recognition by society because a modern sustainable society could not flourish and develop without them. In turn, it is the geodiversity of these resources and their brilliant utilization by humans that have allowed modern society to evolve. (GRAY, 2011)

As questões que envolvem o desenvolvimento de um paradigma sistêmico tem maior relevância nas abordagens geográficas dos anos de 1950, quando os estudos prussianos concentraram-se na abordagem da paisagem, assim a análise direcionou-se aos complexos territoriais, ou seja, aos Geossistemas. Tais categorias de análises serviram ao propósito de entender a natureza de forma complexas. (RODRIGUEZ, SILVA, VICENS, 2015; RODRIGUEZ; SILVA, 2013; RODRIGUEZ et al, 2004). Para os autores Rodriguez, Silva, Vicens (2015) a obra de Victor Sochava tratou:

[...] de incorporar de um jeito integral a abordagem sistêmica no estudo das paisagens como unidades espaciais, como entidades totais, considerando que a organização sistêmica é algo inerente à natureza e à superfície do globo. Fundamentado nessa concepção ele introduz mudanças em diferentes temáticas, não apenas na Ciência da Paisagem, mas também na Geografia em geral. (RODRIGUEZ, SILVA, VICENS, 2015, pág. 226).

A possibilidade de operacionalizar as categorias paisagem e geossistemas tem grande relevância no entendimento das relações entre as temáticas de geologia, geomorfologia, Pedologia, das quais cercam a metodologia da Geodiversidade (seria as conexões entre os elementos que os anima e os diferencial). De outras formas, a operacionalização da dinâmica crustal (Geologia), processos modeladores do relevo (Geomorfologia), a resposta do clima superatuando na formação do Solo (Pedologia) forma todo um complexo natural.

O instrumental que auxilia no entendimento sistêmico da geodiversidade envolve ainda técnicas dos sistemas de informação geográficas em uma perspectiva de uma cartografia digital, que leva em consideração software de geoprocessamento e cenas de radar e imagens órbitais.

Foram utilizados imagens de Radar Sintético (SRTM-DEM) do USGS e as imagens pancromática de $15 \mathrm{~m}$ do Sensor OLI do Satélite Landsat, geoprocessadas no software Argcis 10.5, licença sobre a responsabilidade do CTIC-Unifesspa, Arquivos shapefile com a 
delimitação das Sub-unidades de Planejamento do Estado do Pará, tudo isso subsidiou um mapa, de primeira aproximação, de Geodiversidade das Unidades de Planejamento (UPLAN), das bacias Itacaiúnas e Tocantins.

Para espacializar as unidades de Geologia, geomorfologia e pedologia (Figura 1), foi realizado um cluster da união de todos os atributos do shapefile das unidades supracitadas (mapa geomorfopedológico). Os atributos de Geodiversidade foram todos somados a fim de gerar o mapa de valores de geodiversidade, foram utilizadas as ferramentas Map Algebra para as somas dos atributos.

Através da fórmula:

$$
\text { Geodiversidade: } \sum_{n=1}^{\infty} \text { (Geologia + Geomorfologia + Pedologia) }
$$

A valorização dos atributos físicos nesse trabalho foi realizada através de uma escala de valores relativos e empíricos de acordo com a relação estrutura geológica, relevo e solos, levando em consideração os fatores de vocação dos aspectos físicos regionais. A exemplo, para este estudo que se dispõe na região do sul e sudeste do Pará a valoração de rochas vulcânicas e metamórficas sobrepõem-se as rochas sedimentares, por sua extensa formação de minérios de ferro, bauxita, cobre, ouro, granito, dentre outros.

Os mapas temáticos ou mapas sínteses são os insumos do mapa de Geodiversidade, as informações de estrutura geológica, dinâmicas de relevo e formação dos solos possibilitam agrupá-los de forma integrada para produzir um mapeamento da Geodiversidade.

O embasamento litológico da bacia pode ser agrupado em três grandes conjuntos de rochas, sendo elas as rochas vulcânicas, metavulcânicas e sedimentares das quais guardam as marcas dos processos tectônicos e neotectônicos que estão presente na história geológica da região amazônica (ver figura 01). 


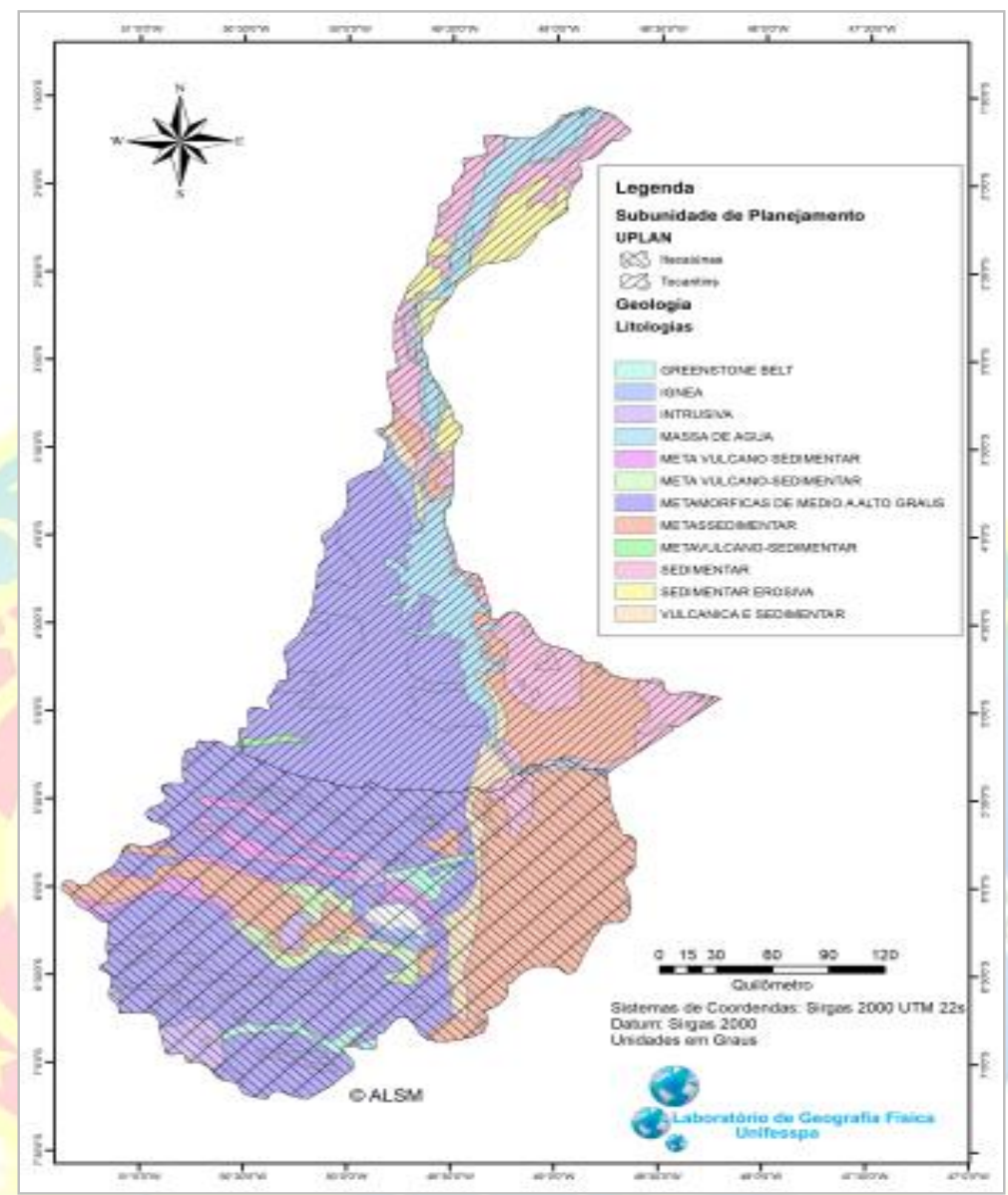

Figura 01. Mapa de Geologia da Unidade de Planejamento Tocantins/Itacaiúnas Org. Autores, 2019

Fonte: CPRM, GEOBANK, 2016

Foram adotados valores de um a cinco (1-5) para medir os graus de importância dos tipos litológicos, esses valorem estão diretamente relacionado a valorização econômica, é sabido que os minerais são dotados de valores econômicos conforme a demanda da sociedade, Por exemplo, as rochas metavulcânicas do complexo Carajás da serra dos Carajás tem minerais como ferro e cobre. Assim ficaram registrados na tabela de atributos do arquivo shapefile.

Os mapas de unidades geomorfológicas seguiram o mesmo padrão de valores (valores 1 a 5) definidos nas unidades geológicas. Tendo forte valor subjetivo a ser valorado, de forma geral adotou o critério de cênico da paisagem, assim, por exemplo, as planícies de acumulação (praias de rios) em toda a calha fluvial, exerce um valor turístico e de uso recreativo, econômico. (ver figura 02). Os pediplanos com as características erosivas tem propensão a formação de cavidades naturais com forte presença de fauna cavernícola e nas vertentes 
podem aparecer quedas d'águas espetaculares que aumentar seu valor geodiverso. Existem alguns elementos do patrimônio natural com valores intangíveis como as grutas ou cachoeiras usadas como lugar de religiosidade (características de valor intríseco).

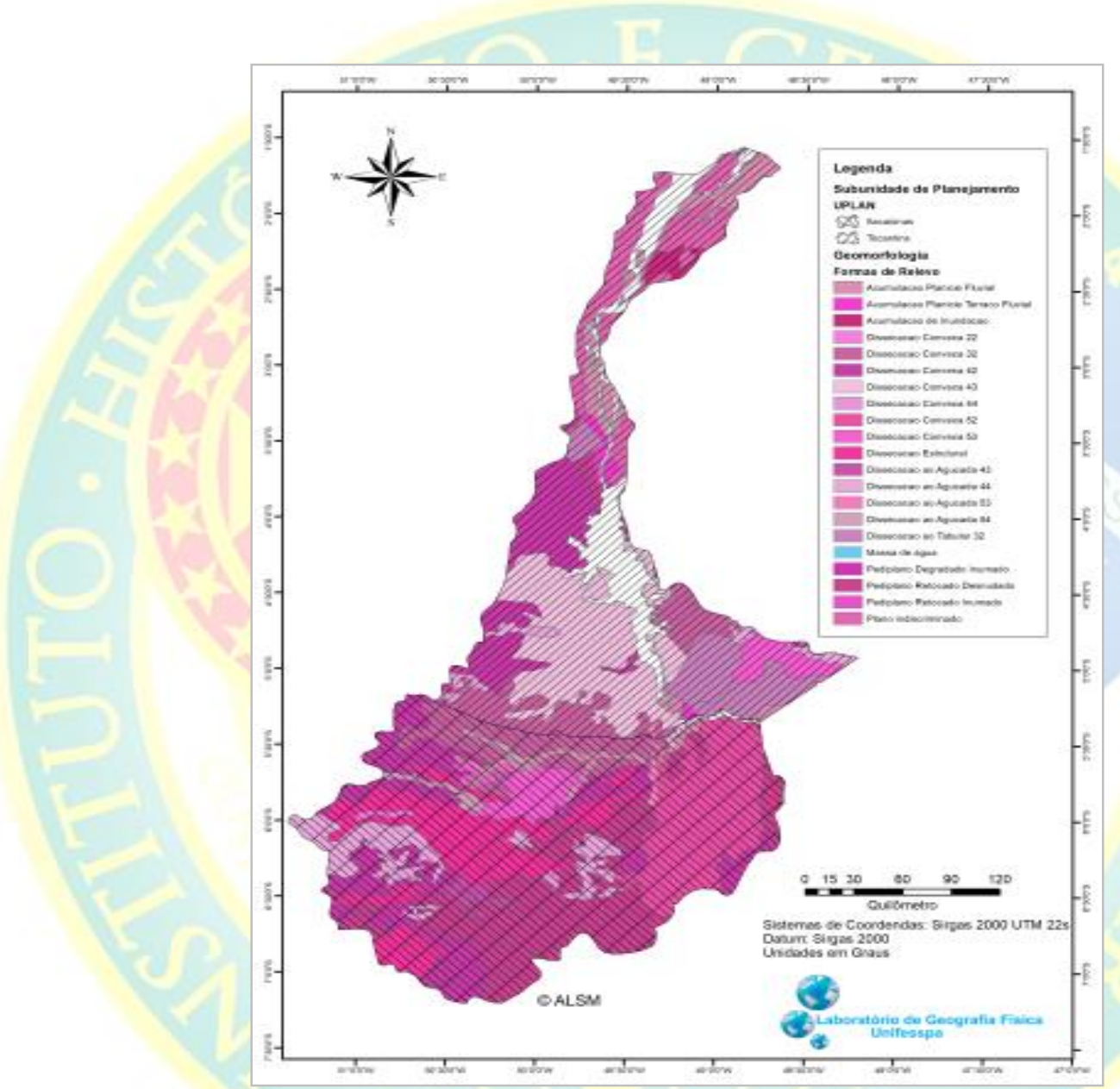

Figura 02. Mapa de Geomorfologia da Unidade de Planejamento Tocantins/Itacaiúnas

Org. Autores, 2019

Fonte: CPRM, GEOBANK, 2016

O Mapa de solo teve os mesmos critérios de valorização dos demais mapas já supracitados. Aqui cabe salientar que os valores tem valoração agronômico e econômica, pois o desenvolvimento da agricultura carece de solos com aptidão agrícola conforme a cultura adotada (valore 3 a 5), ou o tipo do solo tem um destino a ser empregado como o uso na industria de cerâmica como é são os latossolos vermelhos ou argissolos (valores 1 a 3) (ver Figura 03) 


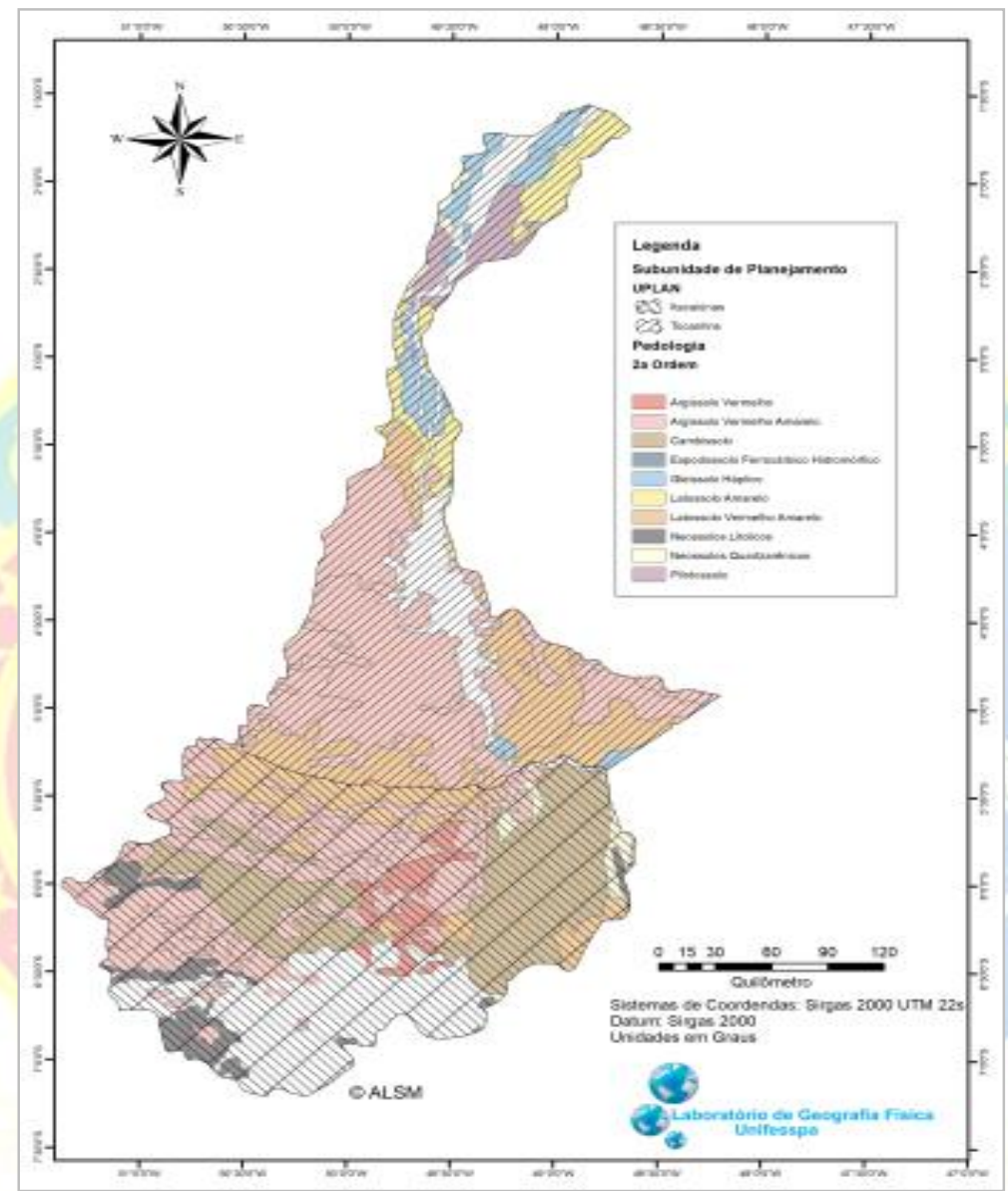

Figura 03. Mapa Pedológico da Unidade de Planejamento Tocantins/Itacaiúnas Org. Autores, 2019

Fonte: EMBRAPA, 2014.

\section{RESULTADOS E DISCUSSÕES}

Quando falamos em Amazônia torna-se unanimidade se reportar a diversidade de vida, quando não muito, fala-se também de um sociobiodiversidade para lembrar a rica cultura que permeia a dinâmica dessa imensa e luxuriante floresta. Mas devemos lembrar que a Amazônia também guarda uma infinidade de recursos minerais, formas variadas de rochas, uma gama de formas de relevo que precisam ser conservadas e protegidas, algumas dessas formas já possuem legislação para isso, é o caso das cavernas e cachoeiras.

$\mathrm{O}$ interesse de uma Geodiversidade foi primeiramente trabalhada e sistematizada por Gray (2004), sua obra traz elementos importantes da geoconservação, do Patrimônio Geológico, ou seja, a herança das estruturas e formas geológicas e a necessidade de conservar o patrimônio geológico. Entende por Geodiversidade a diversidade formada pela reunião do sistema de relações e interrelações geológicos, geomorfológico e pedológico. (GRAY, 2018). 
Esse conceito é importante, pois, aglutina as questões dos Serviços ambientais, mas em uma perspectiva de compreensão da história ecológica da Terra (SALGADOLABOURIAU, 1994), a evolução da vida e da morfogênese através da geologia e geomorfologia do Planeta. (GRAY; GORDON e BROWN, 2013).

$\mathrm{Na}$ perspectiva de construir elementos capaz de valorizar a geodiversidade Gray (2004) destaca cinco valores que estão em associação:

- Valor Intrínseco: é o valor que envolve dimensão ética e filosófica, portanto, é de difícil valoração, pois tem valores por si, a Geodiversidade tem valor em si, pois não há trabalho humano envolvido, portanto, não há como ser mediada pela força de trabalho, seu valore estaria associada aos serviços ecossistêmicos, logo subjetivo em relação ao seu valor que é inerente ao que a geodiversidade oferece. Assim, deve haver uma distinção entre geodiversidade como uma qualidade sem valor, e patrimônio geológico como aqueles, cujo, elementos da geodiversidade vistos como de significativo valor. (GRAY; GORDON e BROWN, 2013);

- Valor Cultural e Estético: o valor cultural é iminentemente social, assim é que, impor valores aos aspectos do ambiente físicos em razão de seu significado social ou comunitário traz a tona os elementos das formas da geodiversidade que valorizam a paisagem, de acordo com Gray (2004), pode-se ter como exemplo a denominação de acidentes geográficos, que tem uma relação com as questões folclóricas, arqueológica e histórica, espirituais, sentido de lugar, como cachoeiras, serras e cavernas que são adjetivadas com nomes teológicos ou de mitos, a exemplo do Poço do Diabo (Serra das Andorinhas-PA), Ladeira do Urso (Terra Indígena Mãe Maria-PA), Cachoeira Spanner (Serra das Andorinhas-PA), entre outras;

- Valor Econômico: a dimensão social do valor econômico de rochas, minerais e sedimentos estão associados a sua raridade e seu grau de pureza ou sua capacidade de ser utilizado em processos industriais. É claro que o desenvolvimento tecnológico impõe valores aos minerais, essa dotação de valor econômico a geodiversidade é sempre social e perpassar pela escala de valor e de uso. Os combustíveis fósseis ou como se refere Gray (2004) os "minerais fuels", têm seu uso na sociedade moderna, entre os mais usuais são o Petróleo, a Tufa e o Urânio. Mas o mercado de gemas tem uma importância significativa no processo de valorização 
econômica por possui valor estético também. Outro mineral importante é a Água, devido as mais diversas tentativas de valorização como mercadoria, o comércio de água engarrafada vem crescendo;

- Pesquisa e valor educativo: a Geodiversidade é sem dúvida lócus da pesquisa e espaço para a produção de valorização dos elementos do patrimônio geológico, o conhecimento produzido a partir dos seus componentes e de sua dinâmica auxiliam nas tomadas de decisões. Gray $(2008$; 2018), chama atenção para a contribuição dos registros geológicos que permitiu aos geólogos reconstruir de forma detalhada a história da Terra ao longo dos últimos 4.600 Ma, Murray Gray afirma que o registro incrível da complexidade da geodiversidade no planeta é uma homenagem ao trabalho meticuloso de milhares de geólogos ao longo de um extenso período de tempo.

\section{A GEODIVERSIDADE NA UNIDADE DE PLANEJAMENTO ITACAIÚNAS E TOCANTINS}

A partir da análise dos atributos dos mapas geomorfopedológico e mapa geológico optou-se em classificar a geodiversidade das Unidades da Bacia em cinco classes (Clusteres), que em associação denotam um padrão de geodiversidade, da qual foi classificada em muito baixa, média, alta, muito alta e altíssima.

Dessa forma o mapa gerado corresponde as características de macro predominância de estruturas geológicas, formas de relevos e manchas de solos. (ver quadro 1). Os valores de Geodiversidade foram agrupados a partir dos atributos de cada elemento de Geodiversidade, assim para a Geologia os elementos estão em associação direta com a origem litológica, para a Geomorfologia foram usados os índices de dissecação e as formas do relevo e para a Pedologia foi levado em consideração a segunda ordem dos solos estabelecidos pela Embrapa (2014).

Quando pensamos em gerenciamento de recursos hídricos, planos de gestão é essencial conhecer as bases físicas da bacia, pois sua geodiversidade influencia de forma direta a localização das jazidas minerais, dos aquíferos, das áreas de vazão, etc. Do ponto de vista da análise da paisagem esses clusteres permitem analisar as funções geoecológicas (área de regulação, área de distribuição, área de concentração de energia, matéria e informação. 
Alhures, subsidia a definição de valores intrínseco, cultural, econômico, estético, valor funcional, valor científico e educativo, elementos importante já discutido por Gray (2004).

A Amazônia revelasse mais uma vez rica em geodiversidade, onde o processo valorativo dos recursos naturais tentam imprimir valores monetários e financeiros, sem pensar em impactos não mensuráveis (valores intangíveis - exemplo: floresta para os indígenas, o rio para os pescadores, a terra para o agricultor), a questão da água é apenas um desses elementos de luta por acesso a água e embate sobre a taxação desse atributo geodiverso. Lembrando que Martinez-Alier (2007), afirma que não existe produção sem geração de externalidade, ou que, o metabolismo social recebe recurso e gera resíduos, o autor é taxativo em afirmar que o mercado não garante o ajuste ecológico.

Quadro 1. Síntese das característica de do Mapa de Geodiversidade.

\begin{tabular}{|l|l|l|l|}
\hline \multirow{2}{*}{ VALORES DE } & \multicolumn{2}{c|}{ ATRIBUTOS DE GEODIVERSIDADE } \\
\cline { 2 - 4 } GEODIVERSIDADE & \multicolumn{1}{c|}{ Geologia } & \multicolumn{1}{c|}{ Geomorfologia } & \multicolumn{1}{c|}{ Solo } \\
\hline Alta & Metavulcânicas & Dissecação Aguçada & Argissolos vermelhos \\
\hline Moderadamente Alta & Vulcânicas & $\begin{array}{l}\text { Dissecações } \\
\text { tabulares+Estruturais }\end{array}$ & Latossolos vermelhos \\
\hline Média & Metamórficas & Pediplanos & Cambissolo háplico \\
\hline Moderadamente Baixa & Metasedimentares & $\begin{array}{l}\text { Planos } \\
\text { indiscriminados }\end{array}$ & Gleissolos háplico \\
\hline Baixa & Sedimentares & Planície Fluvial & $\begin{array}{l}\text { Neossolos } \\
\text { quartzarênicos+litólicos }\end{array}$ \\
\hline
\end{tabular}

Fonte: CPRM, GEOBANK, 2016, EMBRAPA, 2014.

Elaboração: Autores.

A figura 2 demonstra que as áreas que estão nos quadrantes Sul e, em uma diagonal oeste-leste é onde podemos encontrar altos à médias valores de geodiversidades nas bacia do Itacaiúnas e Tocantins. Os baixos valores encontrados não podem significar baixa importância econômica ou falta de valorização intrínseca, mas deve refletir em elementos paisagísticos valorativos, ou seja, devem refletir a diversidade das estruturas e funções da paisagem.

A cartografia de Geodiversidade refletiu uma espacialização diferente entre as duas subunidades de planejamento, essa concentração de Geodiversidade enquanto o patrimônio geológico orientou a exploração de minerais no complexo da província mineral de Carajás, 
mas em contrapartida os valores de médio a muito baixa geodiversidade não impediu o aproveitamento de produção de energia elétrica (Usina Hidroelétrica de Tucuruí) e, de exploração mineral, como areia, seixo e cascalho.

As regiões hidrográficas definidas pela lei estadual dos recursos hídricos do Pará são territorialmente muito extensas, sendo necessário pensar elementos de uma gestão que possa compatibilizar setores/municípios que tenham dinâmicas mais próximas de cada realidade municipal - Talvez seja necessário compatibilizar os usos de cada um dos setores.

A mineração, a pecuária e as áreas de assentamentos devem ser as áreas de maior desafio a gestão das regiões hidrográficas pois possuem objetivos diferentes, por isso o cenário para o desenvolvimento de esforço na administração de conflitos será a tônica da gestão dos recurso hídricos, esse desafio deve ter como grande tema transversal a Geodiversidade compatíveis com a exploração dos demais recurso naturais. De outra forma, ter a visão sobre os grandes empreendimentos regionais permite ampliar as perspectivas sobre a região. 


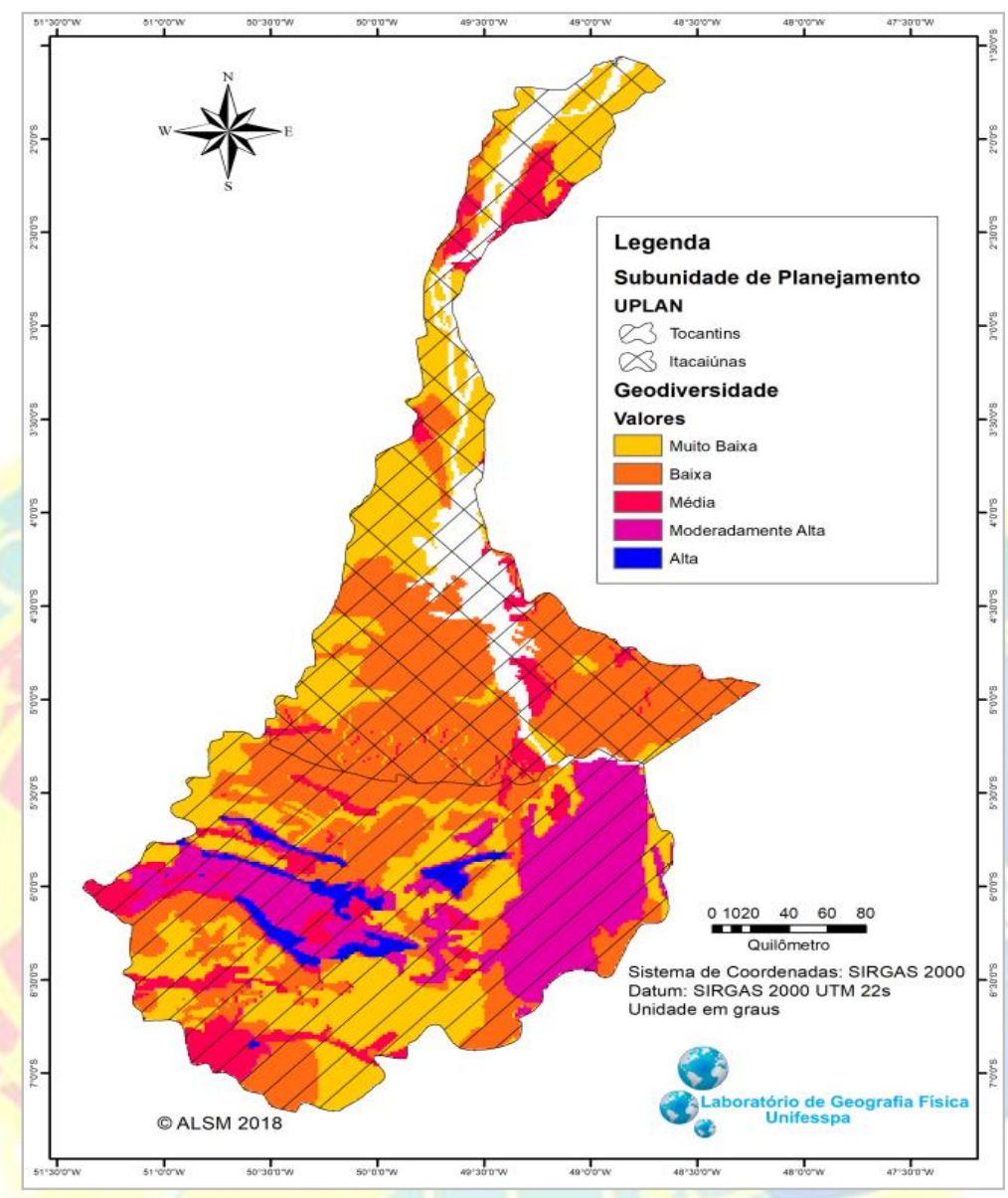

Figura 2. Mapa de Geodiversidade das Subunidades de Planejamento Itacaiúnas e Tocantins do Estado do Pará

Elaboração: Autores, 2018.

\section{CONSIDERAÇÕES FINAIS}

A bacia hidrográfica como unidade de planejamento se consolidou entre os planejadores, seu poder integrativo orienta pesquisas, análises e propostas de uso racional dos recursos naturais e possibilita construir padrões de paisagens que possuem atributos de geodiversidade. O conceito de Geodiversidade complementa e coloca no mesmo patamar de igual a diversidade de vida e diversidade do patrimônio geológico.

A associação dos atributos da geodiversidade foi essencial na distribuição de manchas nas bacias hidrográficas, suas áreas refletem a associação de elementos geológico, geomorfológicos e pedológicos, sua importância estar na realidade ligada ao fato de que a 
natureza dos componentes abióticos deve ser levado em conta no processo de gestão dos recursos hídricos.

O uso do Sistema de Informação Geográfica é infinitamente variado, a potência da ferramenta auxiliada pela metodologia coerente, traz agilidade e confiabilidade nos produtos cartográficos. O uso de Geotecnologias devem ser utilizadas para análise e decisões espaciais, mais isso não significa que temos menos autonomia para decidir os rumos de nossas ações, muito pelo contrário, ela, nos torna mais preparados para fortalecer nossas ações no território.

A metodologia de associar os diversos atributos da geodiversidade a padrões espaciais aglutinados em Clusteres foi primordial na definição das áreas de maior ou menor geodiversidade, havendo a necessidade de uso de definição de indicadores de novas áreas de geodiversidade nas unidades de planejamento aqui em tela. Essa primeira aproximação deve passar por um refinamento metodológico em um segundo momento, apesar de já ter demonstrado ser viável pensar em clusteres de geodiversidade.

Há bastantes literaturas sobre quantificação de geodiversidade pelo mundo, muitos desses trabalhos fazem referência à esplendorosos elementos rochosos ou em arenos-argilosos envolvendo elementos da paisagens. Os estudos de paisagem com foco na geoecologia ${ }^{4}$ vêm se debruçando nos estudos de quantificação muito útil a auxiliar medidas de gestão dos recursos naturais. Contudo os aspectos geológicos, geomorfológicos e pedológicos vêm se revelando bastante promissor para a definição de geositios, geoparques e geomorfositios.

Aqui recai a importância de associar patrimônio natural e as questões das paisagens vista pelo viés da Geoecologia - sua marca principal estar em analisar, representar e definir padrões e processos sistêmicos de padrões paisagísticos ancorados em uma geografia física aplicada ao meio ambiente, de outra forma, a busca de padrões e comportamentos da paisagem como reflexo da atuação humana sobre os elementos da natureza - aqueles ditos complexos naturais trás a baila o conceito de geossistema e sua operacionalidade através dos sistemas de informação geográficos e na representação dos elementos paisagísticos que os animas.

A quase ausência de valores de geodiversidade para as bacias hidrográficas tem contribuído para pouca importância de se ter essa variável em planos de gerenciamento de

\footnotetext{
${ }^{4}$ Os estudos de paisagem como um sistema em funcionamento expressa-se por seus geofluxos que atuam no espaço exercendo funções determinantes no sistema, diretamente relacionada à criação de produtos tem forte apelo dos estudos de geossistemas que traz referencias a uma dinâmica natural da paisagem. ver a tese de doutoramento de Vidal (2014), defendida no Departamento de Geografia da Universidade federal do CearáBrasil que traz uma vasta bibliografia sobre a Ciência da Paisagem ou da Geoecologia das Paisagens.
} 
recursos hídricos e de fortes políticas de controle de exploração de recursos naturais próximos de ambientes de cavernas.

\section{REFERÊNCIAS BIBLIOGRÁFICAS}

EMBRAPA. Sistema Brasileiro de Classificação de Solos, 4ª Ed., Brasília, 2014

GRAY. Murray. Geodiversity: valuing and conserving abiotic nature. John Wiley \& Sons Ltd, The Atrium, Southern Gate, Chichester, West Sussex PO19 8SQ, England. 2004.

Other nature: geodiversity and geosystem services. Environmental Conservation, 38 (3): 271-274. Foundation for Environmental Conservation. 2011.

Geodiversity: the origin and evolution of a paradigm. In: BUREK, C. V. \& PROSSER, C. D. (eds) The History of Geoconservation. Geological Society, London, Special Publications, 300, 2018.

Geodiversity: a new paradigma for valuing and conserving Geoheritage. In: Geoscience Canada, Vol 35, n2, 2008.

GORDON. John E; BROWN. Eleanor J. Geodiversity and the ecosystem approach: the contribution of geoscience in delivering integrated environmental management. In: Journal Proceedings of the Geologists' Association, 124, 2013.

MARTINEZ-ALIER, Joan. Ecologismo dos pobres. São Paulo, Contexto, 2007.

PARÁ. Política Estadual de Recursos Hídricos e Sistema Estadual de Gerenciamento de Recursos Hídricos. Lei $\mathrm{n}^{\circ}$ 6.381, de 25 de julho de 2001, dispõe sobre a Política Estadual de Recursos Hídricos, institui o Sistema Estadual de Gerenciamento de Recursos Hídricos, e dá outras providências.

RODRIGUEZ, J. M. M. et al. Geoecologia das Paisagens: uma visão geossistêmica da análise ambiental. Fortaleza: Editora UFC, 2004.

; SILVA, E. V. Planejamento e Gestão Ambiental: subsídios da geoecologia das paisagens e da teoria geossistêmica. Fortaleza: Edições UFC, 2013.

$17, \mathrm{n}^{\circ} 33,2015$.

SILVA, E.V.; VICENS. R. S. O legado de Sochava. Nossos Clássicos. Ver. GEOgraphia, ano.

SALGADO-LABOURIAU. Maria Léa. História ecológica da Terra. Blucher: São Paulo, 1994.

TOZI. S. C.; MASCARENHAS. A. L. S.; POLÉN. R. R. Água, conflitos e política ambiental na Amazônia legal brasileira. Revista NERA, Presidente Prudente ano 21, n. 42, pp. 228-255 Dossiê 2018.

VIDAL. M. R. Geoecologia das paisagens: fundamentos e aplicabilidades para o planejamento ambiental no baixo curso do rio Curu-Ceará-Brasil. UFC, Centro de Ciências, Programa de PósGraduação em Geografia, Fortaleza-Ceará. 2014. 